\title{
ICT Green Alignment: New Generation Model Based on Corporate Social Responsibility and Green IT
}

Rachid Hba, Abdellah El Manouar

ENSIAS Engineering School, Mohammed V University in Rabat

Morocco

rachid_hba@um5.ac.ma

manouar@ensias.ma

ABSTRACT: The current context of information and communication technology (ICT) alignment is characterized by strong environmental and societal incentives and constraints to reduce carbon footprint. Companies must therefore reorient their ICT alignment strategies towards a new sustainable mode to maintain the performance of innovation, transformation and differentiation flows. This perspective opens up a new field of research, which takes into account the interactions with the stakeholders, as well as a better adjustment of the technological, the economic and the social. In this paper, we present the "ICT Green Alignment" model as a new generation ICT management model. This model is developed according to a Green IT and Corporate Social Responsibility (CSR) approach, which provides a theoretical tool for designing renewed managerial strategies for Sustainable Development (SD).

Keywords: Alignment, Green IT, Corporate Social Responsibility, Sustainable Development, Information and Communication Technology

Received: 2 January 2018, Revised 11 February 2018, Accepted 9 February 2018

DOI: $10.6025 / \mathrm{ijwa} / 2018 / 10 / 2 / 64-73$

(C) 2018 DLINE. All Rights Reserved

\section{Introduction}

Strategic Alignment expresses the idea of establishing and following a cape [REF_15], it applies to two elements in companies: the company strategy and the ICT strategy. The strategic alignment of ICT aims to bring the ICT strategy into line with the company's strategy and to plan in a multi-year perspective. Strategic alignment of ICT involves two necessary conditions:

- Understanding and integration of the company's strategy by the IT function as a whole (structures, organizations and tools).

- Taking account of ICT constraints and opportunities in the company's strategy. 
In addition, the strategic alignment of ICT is needed in the enterprise because it provides a framework for strategy formulation as well as its implementation. According to [REF_21], the company can seek and obtain higher performance as well as a competitive advantage, by setting up a combined business and ICT alignment plan through direct mapping of the ICT strategy with one or more business strategies. This alignment plan requires the ability to acquire and deploy resources that are consistent with the organization's competitive needs [REF_5]. Therefore, the alignment process requires sharing information about organizational goals and objectives at different levels and within different units of the organizational hierarchy. The company is constantly invited to gather and reconfigure internal and external skills to adapt to ever-changing business environments.

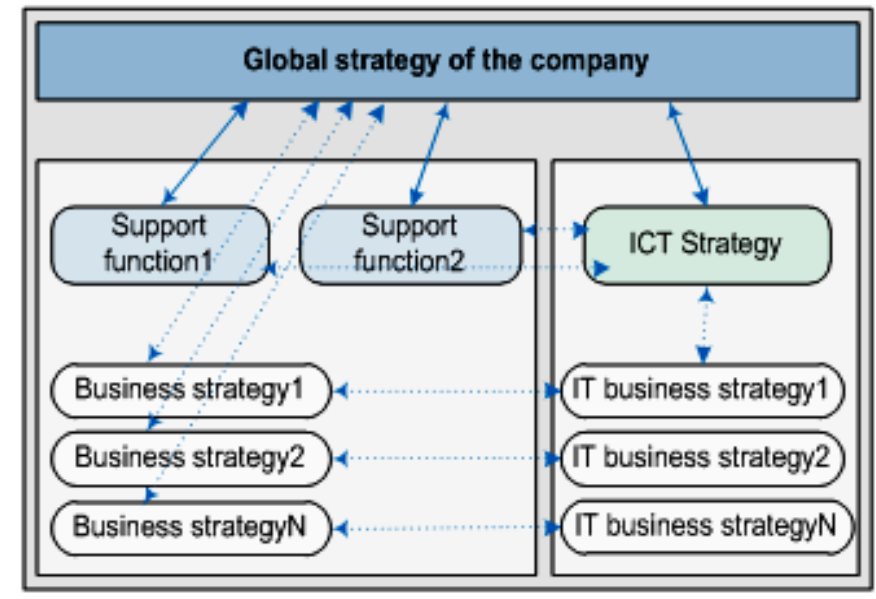

Figure 1. Alignment of business and IT functions

For decades, the strategic alignment of ICT with the company's global business strategy has been the subject of extensive research. Indeed, this field is a vast subject far from being exhausted, as ICT is no longer just a way of streamlining the flow of production. Business activities and processes are based on increased use of ICT [REF_15], resulting in new strategies and new competitive advantages. However, despite the many researches in this field, the impact of the strategic alignment of ICT on economic, social and environmental performance remains unexplored, ac-cording to the results reported in the literature and which remain mixed. In this thesis, we will advance our under-standing of mixed results in research on ICT alignment through the proposal of a new alignment model based on Green IT and CSR.

The strategic alignment of ICT is the basic process of re-structuring the IT organization and processes and the production system so that they are in perfect harmony with the overall strategy that has been put in place by the managers of the company. ICT alignment therefore also results from the joint coherence between strategic choices (strategic alignment), organizational design (structural alignment) and the use of ICT (technological alignment). This definition has its origins in the theory of contingency which states that the performance of the enterprise is the result of the congruence between one or more factors. According to [REF_12], the strategic alignment model assumes that the ICT strategy must be consistent with the overall business strategy in order to achieve improved performance.

\section{Theoretical Context and Literature Review}

\subsection{SAM model positioning: Strategic Alignment Model}

As noted in the previous section, models derived from contingency theory are based on processes that provide a framework for exploiting theories and research findings on the interrelationships and characteristics of organizations [REF_12]. In this section, we present only the few ICT alignment models that have been particularly influential. We focus on the research that emerged in the early 1990s from North America and Europe. Many studies have subsequently used the concepts of these models. Research conducted prior to the 1990s was the first attempt to harness the strategic power of ICT [REF_13]. This work has argued that a revolutionary change involving investment in ICT can yield consistent benefits as long as the key elements of strategy, technology, structure, management processes and individuals. In particular, researchers focused on the position of the ICT alignment strategy and its implementation, which is seen as a vector for strategic external integration [REF_12] and also for functional integration [REF_13] by physically decompartmentalizing the company from its environment. 
In 1993, Henderson and Venkatraman professors at the MIT Sloan School of Management in Boston found that there was a consequent lack of fundamental frameworks to understand the potential of ICT for organizations in the future [REF_19], despite the change in role that ICT can play, moving from a supportive role to a strategic one. The Strategic Alignment Model (SAM) was therefore constructed by these authors in order to overcome this lack by modeling the new strategic era of ICT that emerged at the time. Their research focuses on the impact of the emergence of ICT on sources of competitive advantage and the organizational interrelationships between strategic and technological planning of these ICT. The concept of alignment addressed by these two authors is based on two assumptions:

- Financial and economic performance is directly determined by an organization's ability to create an adjustment between the organization's position and the adoption of an appropriate administrative structure to support its execution.

- The cited adjustment is characterized by dynamism and the process of alignment is in full change and continuous adaptation. To achieve this dynamic capacity, there must be organizational arrangements to put in place the appropriate technologies to create differentiation in the activities of the organization.

The concept of ICT alignment according to the SAM model is articulated and aims to find coherence around four fundamental areas of management [REF_12]:

- Business Strategy: Defines the company's positioning in its market (product / market), its distinctive competencies and its business.

- ICT Strategy: Corresponding to the choice of ICT and the governance mechanism.

- Infrastructure and Organizational Processes: Is interested in the design of organizational structures: administrative structure, definition of business processes.

- ICT Infrastructure and Processes: Covers the portfolio of applications, managerial and technical skills related to ICT, infrastructure, technological development processes.

From these four dimensions-domains, the strategic alignment model SAM proposes to ensure the coherence of strategic choices according to two main axes:

\section{Strategic Adjustment}

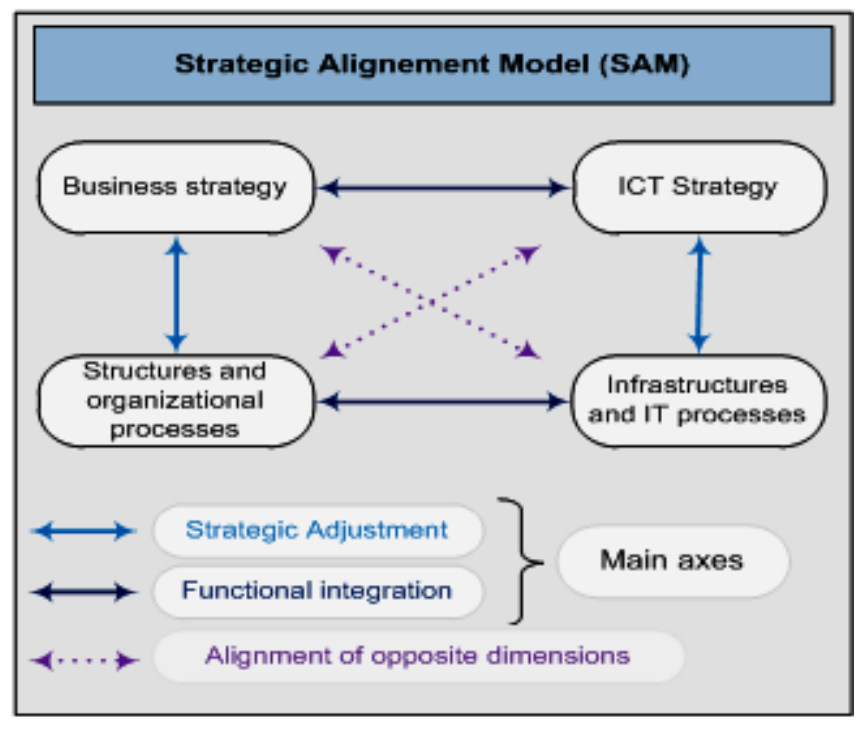

Figure 2. SAM Model "Strategic Alignment Model" 
It is interested in the alignment between external do-mains and internal domains. Indeed, there must be coherence between the company's strategy and the organizational structure on the one hand, and coherence between the IT strategy and the ICT implemented on the other. This Adjustment identifies the need to manage the choices that position the company on an external market and decide how best to structure the company's internal arrangements to execute this market positioning strategy. Choices that position the company in a marketplace are referred to a business strategy and those that determine the internal structure of the business as organizational organizations and processes.

\section{Functional Integration}

It corresponds to the integration of the business domain and the technological field. It represents the horizontal relationship, which is an extension of the notion of strategic adjustment to the functional area of the strategic alignment framework. As business strategies change, IT strategies and processes must also keep pace and correspondingly, the infrastructure and processes need to keep pace with the change in business or ICT.

The relevance of the model is justified through these two fundamental axes of strategic management, which are: strategic adjustment and functional integration. The first axis refers to the adjustment that must be made between the external positioning of the organization and its internal commitment [REF_12]. To position oneself, the company must define the scope of the adoption of the ICT that it must put in place, the systemic competences that it must have, and a governance of these ICT. At the same time, it must also make choices for its internal agreement concerning the definition of ICT architectures, implementation of processes and IT skills. The second fundamental axis of the model is aimed at both the strategic integration and the operational integration of the business and IT domains.

The alignment of the opposite dimensions describes:

- Alignment between business strategy and IT infra-structure and processes represents a traditional linking view that requires the specification of work processes, roles, and authority structures to report how products and services will affect the business strategy. That is, the business strategy must be broken down into a work process to define the requirements of IT infrastructure and processes.

- Alignment between IT strategy and organizational structures and processes reflects a vision of automating the work environment. This represents the potential of ICT to change organizational processes. This vision focuses on the potential value of ICT and how IT infrastructure and processes provide a service organization to support that potential.

The SAM model offers four dominant perspectives of alignment. These perspectives were conceived on the basis of the two aforementioned axes and the relations between the four domains which are necessarily multivariate relations:

\section{Business Strategy}

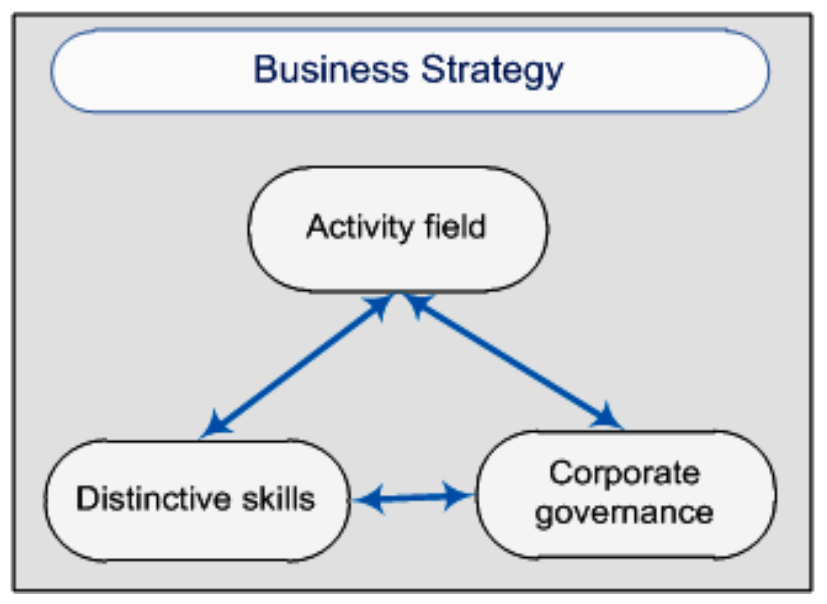

Figure 3. Perspective 1 of the SAM model 
Activity Field: Includes markets, products, services, customer groups and sites where a company • potential competitors that affect the business environment.

- Distinctive Skills: Critical success factors and core competencies that provide a business with a potential competitive advantage. This includes the brand (type of product manufactured by a particular company), research, manufacturing and product development, cost and price structure, and sales and distribution channels.

- Corporate Governance: How companies establish the relationship between management, shareholders and the board of directors. The inclusion of the company is also influenced by government regulation and how the company manages its relationships and alliances with strategic partners.

\section{Infrastructure and Organizational Processes}

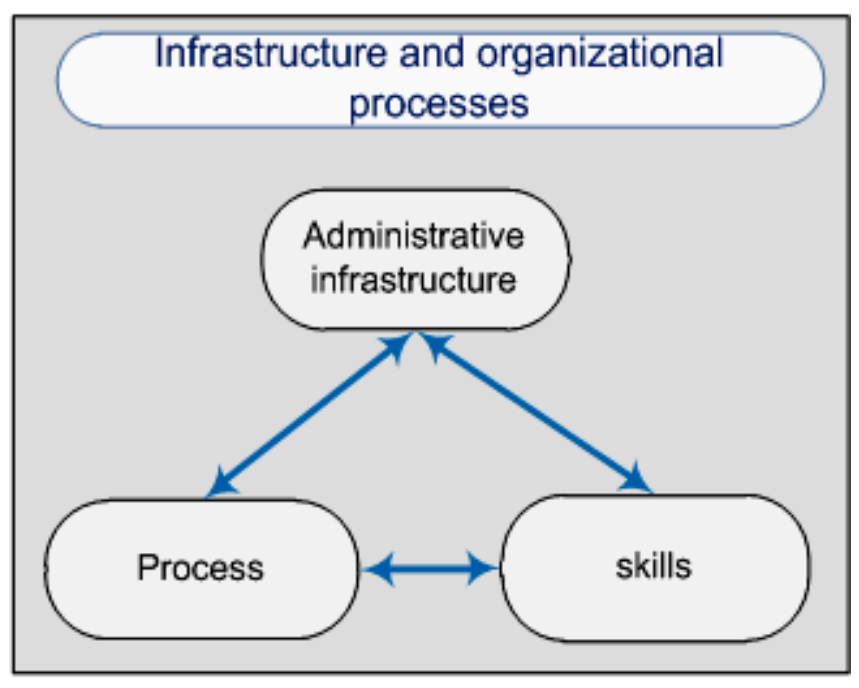

Figure 4. Perspective 2 of the SAM model

- Administrative Infrastructure: How the company organizes its activities (central, matrix, horizontal, vertical, geographic, federal ad functional).

- Process: How the business activities of the company (the work done by the employees) work. Key issues include value-added activities and process improvement.

- Skills: Human resource considerations such as hiring, motivating, training, educating and cultivating.

\section{IT Strategy}

- Technological Scope: The important applications and ICT put in place.

- Systemic Skills: These capabilities (for example, access to information that is important to the creation / execution of a company's strategies) that distinguish IT services.

- IT governance: How to manage resources, risk, conflict resolution and ICT responsibility is shared among business partners, ICT management and service providers. Project selection and prioritization issues are included here.

\section{IT Infrastructure and Process}

-Architectures: Technology priorities, policies, and choices that enable applications, software, networking, hardware, and data 


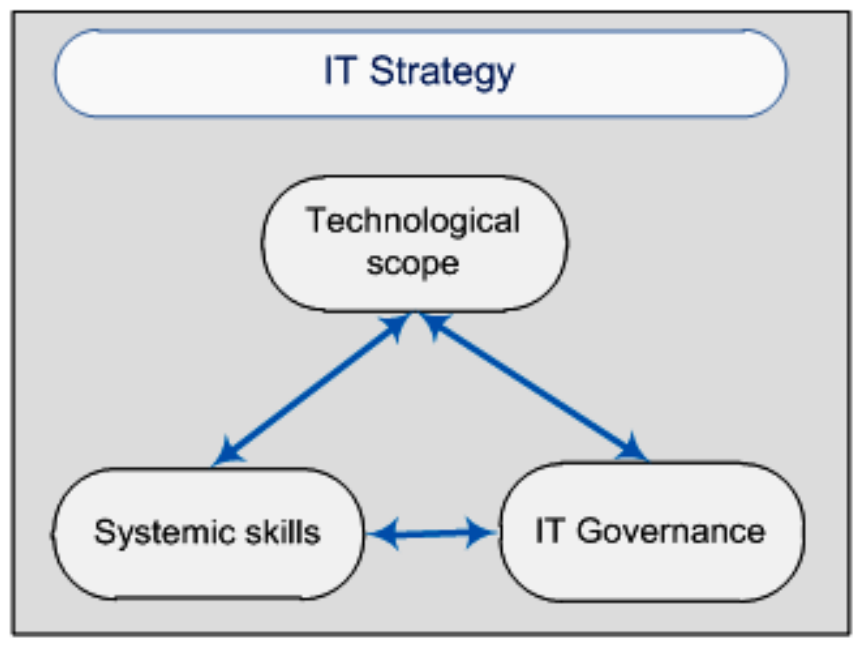

Figure 5. Perspective 3 of the SAM model

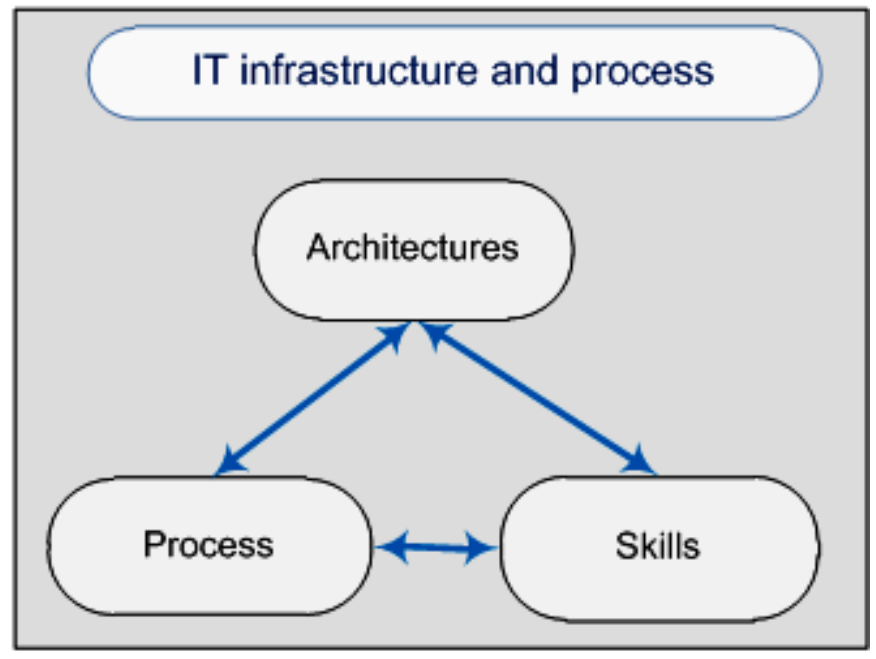

Figure 6. Perspective 4 of the SAM model

management to be integrated into a consistent platform.

- Process: Practices and activities to develop and maintain applications.

- Skills: Human resource considerations in IT terms, such as how to hire, motivate, train or educate and culture.

\subsection{Positioning Synthesis}

Below we present the characteristics of the SAM approach of ICT alignment that we studied in this thesis. This is a summary that will help us in the development of the new alignment model:

- A reference for the majority of academic publications on the subject.

- This model is built in two dimensions: strategic adjustment and functional integration.

- The challenge is to make ICT an asset in the service of the company's business strategy. 
- According to the model the notion of alignment is complex and can go beyond the link between ICT and business strategy.

- Identifies the external perspective of ICT (IT Strategy) from its internal development (IT infrastructure and process).

- Provides a global definition of strategic alignment.

- Uses Balanced Scorecards.

- Causal approach that allows the study of phenomena related to alignment (influence on the performance of companies).

- The SAM model does not provide a construction or instrument for measuring and evaluating alignment.

- The SAM model does not take into account the sustainability aspect (CSR and Green IT) in the ICT alignment approach.

\section{ICT Green Alignment Model}

\subsection{Problem and Working Hypothesis}

The implementation of Green IT practices and the CSR strategy can have the capacity to contribute to the achievement of SD objectives through the implementation of eco-responsible ICT alignment initiatives. As stated in the SAM Model Synthesis, the alignment approach was not easy to conduct, because its adoption in a holistic way involves multiple stakeholders, forcing policy makers to adopt a more dynamic and cross-cutting approach. In addition, it is necessary to design strategies in a sustainable way and in line with business objectives.

We therefore need an ICT alignment model that pro-vides an effective framework for integrating the concepts of CSR objectives and Green IT. The process of ICT alignment involves multiple stakeholders in an increasingly complex system, making it more difficult to define a framework that can contribute to the enrichment of managerial models. The ICT Green Alignment model is based on Green IT and CSR, which improves the lifespan of relation-ships with all stakeholders [REF_20, REF_22]. It also ensures the sustainability of resources [REF_8, REF_9] and constitutes an effective managerial framework.

\subsection{New Proposed Model}

In the following of this paper we will try to fill the gap in the literature on the subject of the strategic alignment of ICT according to the CSR approach and Green IT. We will provide a new alignment model that can be used to describe strategic alignment strategies redesigned according to a Green IT and CSR-based SD strategy. To do this, we will adopt a holistic approach that extends the concept of "Balanced Scorecard", developed by Kaplan and Norton [REF_16] in 1992. This concept was based on four perspectives: customer, finance, business processes, growth and learning.

We propose to modify this concept to take into account the integrated strategy of Green IT and CSR that we presented. This approach is proving more effective, which, thanks to the practices of Green IT and CSR, makes it possible to improve the ICT alignment process by playing a central role in the creation of value towards all the stake-holders.

We introduce the "ICT Green Alignment" model that we have designed on the following three pillars: ICT strategy, business strategy, societal and environmental strategy, these three pillars are aligned according to the Green IT and CSR approach:

In Figure 7, the ICT strategy is aligned with the concept of Green IT and CSR to achieve the goals of SD and technology efficiency (carbon footprint) and value creation. This strategy encourages the creation of new forms of management based on $\mathrm{SD}$, which requires the implementation of the societal and environmental strategy, which in turn makes it possible to create differentiation and to improve technological and organizational practices in an innovative way.

\subsubsection{ICT Strategy}

The concept of Green IT should be integrated into the theoretical framework of the ICT strategy to facilitate the link between environmental IT practices and the strategic context of the enterprise. The ICT strategy articulates how the application of IT is expected to meet the organization's requirements by providing efficient IT processes and services to the business, supporting business objectives, and providing value. The ICT strategy must therefore refer to the specific competitive environment of the company and its business objectives.

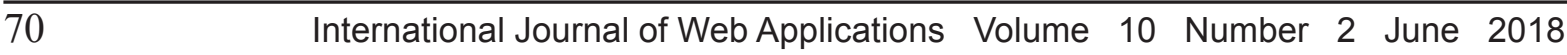




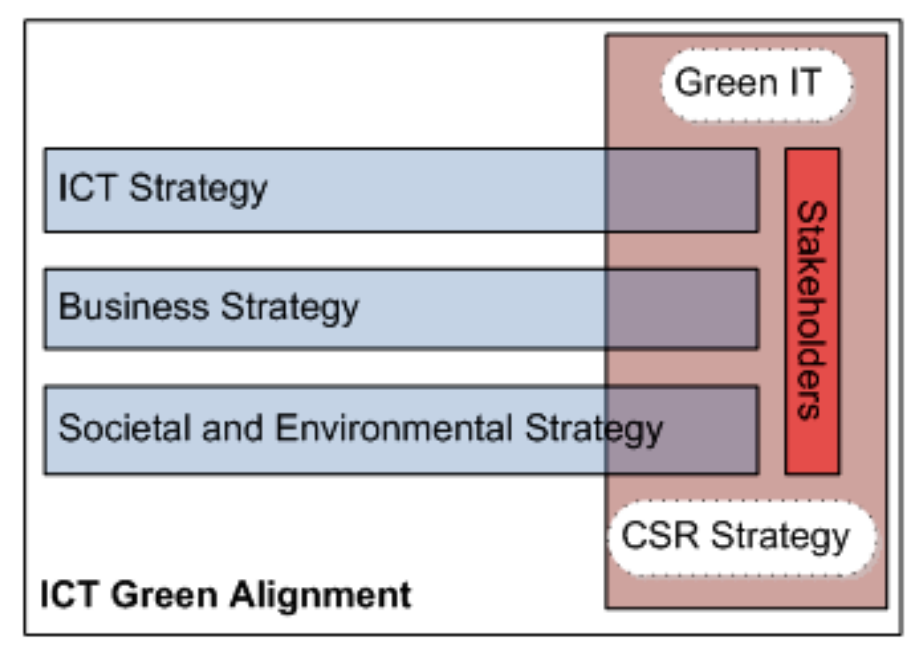

Figure 7. "ICT Green Alignment” model

The ICT strategy takes into account the costs, risks and opportunities of currently available and future ICT and needs to assess their potential business impact. Competitive advantage must be considered from two dimensions: the internal dimension, where ICT can enable profitable business processes, and the external dimension, where ICT can be used to deliver unique customer value [REF_6]. The ICT organization should be efficient and effective in providing internal and standardized technology solutions while developing distinctive solutions focused on the external business environment.

We propose a definition of the ICT strategy that focuses on the Green IT and CSR strategy. This concept is sup-posed to allow a holistic IT management taking into ac-count the strategic objectives and the environmental aspects. On the one hand, this strategy ensures that IT systems and applications meet the demands of the business. This is aimed at optimizing the IT architecture taking into account efficiency and functionality.

\subsubsection{Business Strategy}

Business value and competitive advantage are created by effective provisioning of services, superior IT services that provide differentiation and technological innovations that create IT-based business opportunities. On the other hand, the ICT strategy is aligned with the SD strategy through the concept of Green IT and CSR, which improves the eco-efficiency of the IT infrastructure. The reduction targets for ICT-related emissions are determined by the objectives of the enterprise SD strategy. In this way, Green IT supports the sustainability of this strategy by facilitating eco-efficiency and competitive differentiation.

In addition, Green IT can create opportunities for environmental technological innovations, which can change current business practices.

Exploiting all the competitive potential requires the strategic alignment of the Green IT strategy and the CSR strategy. At this point, we have decided to refer to generic choice-based environmental competition strategies, which are closely aligned with our understanding of business strategy, value creation and the competitive advantage of environmental initiatives.

\subsubsection{Societal and Environmental Strategy}

Our model is based on the logic and basic procedures of the SAM model, which joins our distinction between internal and external sources of competitive advantage. The eco-strategy model, in its "ICT Green Alignment" dimension, is conceptualized in order to identify the sources of competitive advantage and thus align green environmental technologies and competitive environmental strategies geared towards outside. This dimension allows the realization of the strategic adjustment that eliminates the current constraints of the strictly internal perspective of Green IT practices and connects the Green IT to the external strategic perspective, integrating the customer and stakeholder aspects and revealing sources of competitive advantage for the product.

Sustainability goals can only be achieved if the strategies are implemented on the basis of an appropriate IT and organizational

International Journal of Web Applications Volume 10 Number 2 June 2018 
infrastructure, which forms the basis of low-impact business processes. The process of functional integration between Green IT and environmental sustainability takes into account the impact of Green IT on the sustainability strategy and vice versa, indicating how Green IT can benefit from the competitive sustainability strategy and how a SD-oriented infrastructure can increase the sustainability of business operations.

We proposed a new Balanced Scorecard approach to implement the "ICT Green Alignment" dimension. Our approach integrates environmental and societal strategy into the strategic alignment process of ICT. The power of the model we propose is reflected in three fundamental perspectives of alignment:

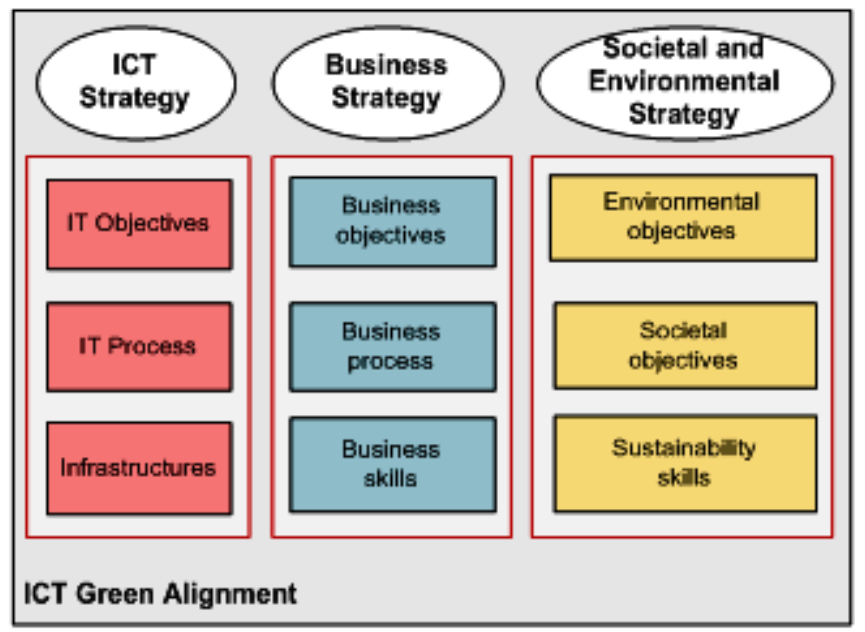

Figure 8. "ICT Green Alignment" Framework

- The first perspective refers to the alignment that must be made between the ICT strategy and the business strategy. To position oneself, the company must define the scope and objectives of the ICTs it must implement to support business objectives and develop business skills and knowledge. The company also needs to build infrastructure and implement appropriate IT processes that can optimize both the execution of ICTs and the optimization of business processes.

- The second perspective aims at aligning the ICT strategy with the societal and environmental strategy. The ICT strategy aims to achieve environmental and societal goals as well as to develop know-how based on sustainability.

- The third perspective of the model is the alignment be-tween the business strategy and the societal and environmental strategy.

\section{Conclusions and Perspectives}

The "ICT Green Alignment" model is built on a holistic research approach, which has led us to focus on transversal modes of ICT alignment to better meet the expectations of all stakeholders. Our innovative approach is based on a simple principle that aims to implement basic SD concepts in the ICT alignment process.

The reflection that we conducted is a first step towards a more thorough and approved approach tested on the basis of a real case study, in order to pilot research in the field of ICT management systems according to the concept of SD. We propose in another step to start from this basic model, to design a new generation ICT alignment repository that will be developed on the principles of Green IT and CSR.

\section{References}

[1] Hba, R., Bakkas, A., El Manouar, A., Janati Idrissi, M. A. (2016). "Eco-strategy: Towards a new generation managerial model based on Green IT and CSR", International Journal of Computer Science \& Information Technology (IJCSIT) 8 (2), (April).

72 International Journal of Web Applications Volume 10 Number 2 June 2018


[2] Hba, R., El Manouar, A. (2017). Eco-strategy: CSR strategy and Green IT updated model for ICT management, International Journal of Scientific \& Engineering Research, 8 (1) (January)

[3] Hba, R., El Manouar, A. ICT Green Governance: new generation model based on Corporate Social Responsibility and Green IT”, VSST2016, $8^{\circ}$ Colloque, VEILLE STRATEGIQUE SCIEN-TIFIQUE \& TECHNOLOGIQUE

[4] Hba, R., El Manouar, A. (2017). Eco-strategy: New ICT management model built on the basis of the CSR strategy and Green IT, International Journal of Computer Science \& Information Technology (IJCSIT) 9 (4), (August).

[5] Ward, J., Peppard, J. (2003) Strategic Planning for Information Systems, Third Edition, John Wiley \& Sons, Chishester, UK

[6] Abernathy, William J., Utterback, James M. (1978). Patterns of Industrial Innovation. Technology Review, 80 (7) 40-47.

[7] Siegel, Donald, S. (2009). Green Management Matters Only If It Yields More Green: An Economic/strategic Perspective. Academy of Management Perspectives 23 (3) 5-16.

[8] Rennings, K., Wiggering, H. (1997). Steps towards indicators of sustainable development — linking economic and ecological concepts. Ecol. Econom. 20, 25-36.

[9] Bieker, T. (2005). Sustainability Management with the Balanced Scorecard, Institute for Economy and the Environmentat the University of St. Gallen, St. Gallen.

[10] Luftman, J. (2004) Key Issues for IT Executives 2004, MIS Quarterly Executive, 4 (2) 269-286.

[11] Ravichandran, T., Lertwongsatien, C. (2005) Effect of Information Systems Resources and Capabilities on FirmPerformance - A Resource-Based Perspective, Journal of Management Information Systems, 21 (4) 237-276.

[12] Henderson, C., Venkatraman, N. (1993) Strategic Alignment - Leveraging Information Technology for Trans-forming Organizations, IBM Systems Journal, 32 (1) 472-484.

[13] Wang, H.-L., Ghose, A. (2006). On the foundations of strategic alignment.The Proceedings of the 2006 Australia and New Zealand Academy of Management Conference. Dunedin, New Zealand, December 2006.

[14] Wang, H.-L., Ghose, A. (2011). Green strategic alignment: Aligning business strategies with sustainability objectives. In B. Unhelkar, ed., Handbook of Research in Green ICT: Technical, Business and Social Perspectives, p. 29-41. IGI Global, Hershey, PA, USA.

[15] Chan, Y. E., Reich, H. B. (2007). IT alignment: what have we learned?, Journal of Information Technology, p. 1-19.

[16] Kaplan, R. S., Norton, D. P. (1992). The Balanced Scorecard: Measures that Drive Performance, Harvard Business Review, (January-February): 71-79.

\section{Author Biographies}

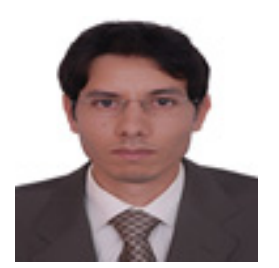

Rachid Hba is a PhD candidate at the National Higher School for Computer Science and System (ENSIAS), Mohammed V University in Rabat, Morocco. The goal of his research is the reflection on the new generation management models. Rachid got a national computer engineer diploma in 2005, from the ENSIAS Engineering School. Rachid worked as a senior consultant in information and communication technology and project management.

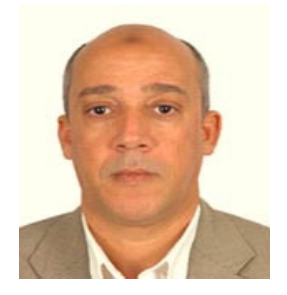

Pr. Abdellah El Manouar holds a PhD in economics from Montreal University in 1991, Canada. He is Professor of Higher Education and Head of Business Intelligence Option and IT department and Decision Support. He is member of TIME research team at ENSIAS Engineering School (National Higher School for Computer Science and System), Mohammed V University in Rabat, Morocco. His research topics cover finance and investment, management and new economy, financial management and financial engineering.

International Journal of Web Applications Volume 10 Number 2 June 2018 